\title{
Opportunities for Prevention of Gestational Diabetes Before 24 Weeks of Gestation
}

This article was published in the following Dove Press journal:

Diabetes, Metabolic Syndrome and Obesity: Targets and Therapy

\section{Decui Cheng \\ Feifei Li \\ Xuexin Zhou \\ Xianming $\mathrm{Xu}$}

Department of Obstetrics and Gynecology, Shanghai General Hospital, Shanghai, 201600, People's Republic of China
Correspondence: Xianming Xu Department of Obstetrics and Gynecology, Shanghai General Hospital, South Hospital of Shanghai General Hospital, 650 Xinsongjiang Road, Songjiang District, Shanghai, 201600, People's Republic of China Email xuxmII@I63.com
Background: Gestational diabetes (GDM), increasingly prevalent worldwide, is related to growing pregnancy complications and long-term metabolic risks for the woman and the descendants. The aim of this study is to determine the optimal BMI ranges specific for age group and optimal gestational weight gain $(G W G)$ at 24 weeks specific for different pre-BMI (pre-pregnancy body mass index) groups to avoid or reduce the incidence of GDM.

Methods: A retrospective cohort study of 3104 pregnant women was conducted in Song Jiang district, Shanghai, China. A multivariate logistic regression analysis was performed with the purpose of determining the OR (odds ratio) of risk factors of GDM including GWG of 24 weeks, pre-BMI, advanced age, and first-degree relatives with DM. Optimal ranges of GWG or pre-BMI are defined as the interval corresponding to lowest or relative lower incidence of GDM.

Results: ORs of pre-BMI, maternal age, GWG at 24 weeks, and first-degree relatives with DM were $1.250,1.096,1.142$, and 2,098 separately. It is suggested for lowering the incidence of GDM that, to the utmost extent, $12 \mathrm{~kg}, 9 \mathrm{~kg}$, and $8 \mathrm{~kg}$ for GWG at 24 weeks should be the ideal boundary for those pregnant women whose BMI was $15-21 \mathrm{~kg} / \mathrm{m}^{2}$, $21-23 \mathrm{~kg} / \mathrm{m}^{2}$, and $23-25 \mathrm{~kg} / \mathrm{m}^{2}$ respectively. Pre-BMI $\leq 22 \mathrm{~kg} / \mathrm{m}^{2}$ would be recommended for an expectant mother whose age is no more than 28 years old. Similarly, women whose age was above 28 years old would be advised to control their BMI below $20 \mathrm{~kg} / \mathrm{m}^{2}$.

Conclusion: Optimal GWG during pregnancy varies largely by diverse pre-BMI, and likewise, optimal pre-BMI varies a lot by different age group. Public health awareness should be promoted on the importance of having healthy pre-BMI, and achieving optimal weight gain during pregnancy to avoid or reduce the incidence of GDM, especially for those with first-degree relatives with DM.

Keywords: gestational diabetes, GDM, pre-BMI, GWG at 24 weeks, age

\section{Introduction}

Gestational diabetes (GDM) is defined as glucose intolerance first diagnosed during pregnancy and is highly correlated with adverse outcomes during pregnancy and the perinatal period. $^{1,2}$ It was reported that those women with GDM would develop type 2 diabetes (T2DM) with 7-fold higher times after delivery 10 years later, ${ }^{3}$ and the offspring of mothers with GDM have a higher risk of developing intellectual problems, obesity, cardiovascular disease (CVD), and diabetes (DM). ${ }^{4,5}$ The global incidence of GDM is increasing and well-documented risk factors for GDM include advanced maternal age, high pre-BMI, GWG during pregnancy, family history of diabetes, ethnicity, history of gestational diabetes, fertility, short stature, polycystic ovary syndrome, history of macrosomia delivery, and high systolic blood pressure, ${ }^{6}$ yet the interaction of each risk factor remains obscure. 
Quite a few studies have now recognized that the attack of GDM might launch as early as 16 weeks while later development of GDM and a baby deemed large for gestational age (LGA) are relevant with a hyperglycemic state of matrix and fetal hyperinsulinemia in the early pregnancy period. ${ }^{7}$ Embryos of pregnant women diagnosed with GDM showed overgrowth compared with those of healthy mothers by oral glucose tolerance test (OGTT), which was conducted at 24-28 weeks of pregnancy, and demonstrated that among women with GDM, early-onset fetal overgrowth might be prone to reversion with early and adequate treatment, ${ }^{8}$ suggesting that intervention should have been performed earlier.

Multiple meta-analyses have demonstrated that lifestyle and drug interventions can lower the chance of hyperglycemia, gestational weight gain, and cesarean section, and possibly reduce gestational diabetes, but do not consistently improve perinatal outcomes. ${ }^{9-11}$ This result may be due to the fact that the intervention period was too late, or the advice for them was not sufficiently precise and personalized. ${ }^{12}$ Therefore, specific and delicate interventions should be set up and implemented as soon as possible.

It was gratifying that the gestational weight gain (GWG) guideline was published by the American Institute (IOM) in $1990^{13}$ and 2009 Revision, ${ }^{14}$ but, regrettably, the application of IOM in Asian populations may be limited as their research was based on studies of white women. Furthermore, the WHO international BMI cut-off points defining pre-BMI categories in the IOM guidelines are not directly applicable to Asians, especially the Chinese. Most importantly, the IOM does not take the pregnancy outcome of GDM into consideration. A study to define optimal GWG ranges of 24 weeks gestation age and pre-BMI focusing on the avoidance of GDM before OGTT was urgently needed for Chinese women.

\section{Methods}

\section{Study Population}

The diagnostic criteria for GDM refer to the IADPSG standard, ${ }^{1}$ which is that pregnant women at $24-28$ weeks of pregnancy (at least 8 hours after fasting) are screened for GDM through $75 \mathrm{~g}$ oral glucose tolerance test (OGTT). If one or more blood glucose values meet or exceed the diagnostic criteria (fasting: $5.1 \mathrm{mmol} / \mathrm{L}, 1 \mathrm{~h}: 10 \mathrm{mmol} / \mathrm{L}$, $2 \mathrm{~h}: 8.5 \mathrm{mmol} / \mathrm{L}$ ) GDM will be diagnosed.
This retrospective case-control study was conducted among women registered at the obstetric department of Shanghai General Hospital from January 2019 to August 2020. The source of data was extracted from antenatal clinic cards of pregnant women having delivered in Shanghai General Hospital. The clinic cards contained the patient's background, antenatal care information, demographic characteristics, and obstetric history. Eligibility criteria are listed as follows: 1) first antenatal care was done before 15 weeks of gestation in our hospital; and 2) the patient's medical history data were complete. The exclusion criteria include: 1) miscarriage or induced labor of deformity; 2) diabetes diagnosed before pregnancy; 3 ) history of gestational diabetes or macrosomia delivery; 4) history of more than 2 times delivery; and 5) complications with gestational hypertension, preeclampsia, or any other chronic diseases.

Based on the inclusion and exclusion criteria, 3104 cases were included in the study, of which 518 cases were diagnosed with GDM (16.69\%). The number of $\mathrm{BMI} \leq 23 \mathrm{~kg} / \mathrm{m}^{2}$ was 2684 , including $368 \mathrm{GDM}$ cases (13.71\%), which represented the prevalence of GDM among pregnant women with normal BMI. Obtained from medical history records of the whole pregnancy period of pregnant women, our research embraces gestation age, height, pre-pregnancy weight, weight at 24 weeks, number of pregnancies, parturition times, whether IVF or not, family history of diabetes, OGTT value, gestational hypertension, thyroid condition, childbirth, newborn gender, etc. At enrollment, we obtained maternal selfreported pre-pregnancy weight and height, from which we calculated the pre-pregnancy BMI. We determined GWG as the difference between self-reported prepregnancy weight and the clinically measured weight recorded around 24 weeks. A multivariate logistic regression analysis was conducted to ascertain the OR of risk factors for GDM including GWG of 24 weeks, pre-BMI, advanced age, and first-degree family history of diabetes. The BMI of the 3104 cases was divided into $15-19 \mathrm{~kg} / \mathrm{m}^{2}$, $19-21 \mathrm{~kg} / \mathrm{m}^{2}, 21-23 \mathrm{~kg} / \mathrm{m}^{2}, 23-25 \mathrm{~kg} / \mathrm{m}^{2}, 25-27 \mathrm{~kg} / \mathrm{m}^{2}$, and above $27 \mathrm{~kg} / \mathrm{m}^{2}$, and following that each layer of BMI was stratified again according to GWG at 24 weeks (<5 kg, 5-6 kg, 6-7 kg, 7-8 kg, 8-9 kg, 9-10 kg, $10-11 \mathrm{~kg}, 11-12 \mathrm{~kg}, \geq 12 \mathrm{~kg}$ ) of gestation to calculate the optimal GWG ranges at 24 weeks of gestation age corresponding to the lowest prevalence rate. In parallel, the optimal BMI range was obtained by stratified age $(\leq 28$ years old, $>28$ years old $)$ first and then pre-BMI $(\leq 17 \mathrm{~kg} /$ 
$\mathrm{m}^{2}, 17-18 \mathrm{~kg} / \mathrm{m}^{2}, 18-19 \mathrm{~kg} / \mathrm{m}^{2}, 19-20 \mathrm{~kg} / \mathrm{m}^{2}, 20-21 \mathrm{~kg} /$ $\mathrm{m}^{2}, 21-22 \mathrm{~kg} / \mathrm{m}^{2}, 22-23 \mathrm{~kg} / \mathrm{m}^{2}, 23-24 \mathrm{~kg} / \mathrm{m}^{2},>24 \mathrm{~kg} / \mathrm{m}^{2}$ ). Therefore, obstetricians can give more accurate and timely guidance about pre-BMI and GWG of 24 weeks to avoid or reduce the risk of occurrence of GDM.

\section{Statistical Analysis}

All analyses were performed using SPPS version 25. The categorical variables were described by frequency and percentage distribution; The quantitative variables were first tested for normal distribution, and then they were described with the mean \pm standard deviation $(\bar{x} \pm s)$. The incidence of GDM equals the proportion of GDM cases in the total number of cases observed in the same period. The disordered categorical variables between the two groups and more than two groups were compared using the chisquare test. An independent $t$-test was carried out on each variable to make a comparison between two groups for continuous variables. The odds ratio (OR) and the 95\% confidence interval (CI) for the GDM were estimated using multivariable logistic regression models across gestation age, pre-BMI, GWG of 24 weeks, and firstdegree family history of diabetes. A $P$ value of 0.05 was considered statistically significant.

\section{Results}

\section{Characteristics of Women}

The average age of the 3104 pregnant women included was $29.31 \pm 3.99$ years old, with 307 women above or equal to 35 years old. The mean height and weight at first prenatal visit was $1.62 \pm 0.05 \mathrm{~m}$ and $54.84 \pm 8.21 \mathrm{~kg}$ respectively, along with women with overweight and obesity accounting for $10.95 \%$ and $2.57 \%$ respectively based on the fact that the mean pre-BMI was $21.00 \pm 2.90 \mathrm{~kg} / \mathrm{m}^{2}$. The average GWG at 24 weeks for all pregnant women and the GDM group was $7.32 \pm 3.32 \mathrm{~kg}$ and $8.28 \pm 4.27 \mathrm{~kg}$ separately. The OGTT value of all women was $4.82-8.84$ $7.44 \mathrm{mmol} / \mathrm{L}$, while $5.45-10.50-9.09 \mathrm{mmol} / \mathrm{L}$ for the GDM group. The proportion of cesarean section and newborn weight of the non-GDM group vs GDM group was $21.31 \%$ vs $27.41 \%$ and $3308.12 \mathrm{~g}$ vs $3363.55 \mathrm{~g}$ (Table 1 ).

\section{Risk Factors for GDM}

Table 2 presents the risk factors among non-GDM and GDM women. The OR of pre-BMI and gestation age for GDM is 1.250 and 1.096, which denotes that obese/overweight women or women with advanced age are much more preferred by GDM. The risk of GDM for these women was further increased if their GWG at 24 weeks was larger as the statistics showed the OR of GWG at 24 weeks was 1.142 . There was a bigger chance of women with a first-degree relative with DM to develop GDM compared with other factors as its OR was 2.098, higher than ORs of other risk factors, unfortunately, which is a factor pregnant women cannot reverse or avoid unless they could choose their biological parents again. No statistical significance was observed for height between non-GDM and GDM women. ${ }^{15}$

\section{Incidence of GDM Based on Pre-BMI and GWG at 24 weeks}

For women whose BMI was $15-19 \mathrm{~kg} / \mathrm{m}^{2}$ and $19-21 \mathrm{~kg} /$ $\mathrm{m}^{2}$, the average incidence of GDM (7.44\% and $\left.12.14 \%\right)$ was much lower than that $(13.71 \%)$ of normal pregnant women. Only when GWG at 24 weeks of these

Table I Characteristics of Women

\begin{tabular}{|l|c|c|c|}
\hline Category & Mean & GDM (n) & Non-GDM (n) \\
\hline Age (years) & $29.31 \pm 3.99$ & $30.89 \pm 4.67$ & $29.00 \pm 3.76$ \\
Height $(\mathrm{m})$ & $1.62 \pm 0.05$ & $1.61 \pm 0.05$ & $1.62 \pm 0.05$ \\
Pre-weight $(\mathrm{kg})$ & $54.84 \pm 8.21$ & $58.99 \pm 9.50$ & $54.01 \pm 7.66$ \\
Weight of 24 weeks $(\mathrm{kg})$ & $62.15 \pm 8.74$ & $67.27 \pm 9.84$ & $61.13 \pm 8.13$ \\
GWG at 24 weeks $(\mathrm{kg})$ & $7.32 \pm 3.32$ & $8.28 \pm 4.27$ & $7.12 \pm 3.06$ \\
BMI $\left(\mathrm{kg} / \mathrm{m}^{2}\right)$ & $21.00 \pm 2.90$ & $22.68 \pm 3.44$ & $20.67 \pm 2.88$ \\
OGTT $(0 \mathrm{~h}(\mathrm{mmol} / \mathrm{h}))$ & $4.82 \pm 0.9$ & $5.45 \pm 1.1 \mathrm{I}$ & $4.48 \pm 0.58$ \\
OGTT (I h (mmol/l)) & $8.84 \pm 2.28$ & $10.50 \pm 2.37$ & $7.91 \pm 1.59$ \\
OGTT (2 h (mmol/h)) & $7.44 \pm 2.23$ & $9.09 \pm 2.60$ & $6.52 \pm 1.28$ \\
Newborn weight (g) & $3317.37 \pm 419.48$ & $3363.55 \pm 472.84$ & $3308.12 \pm 407.43$ \\
Newborn sex (male/female) & $1483 / 1621$ & $245 / 273$ & $1238 / 1348$ \\
Cesarean section (yes/no) & $693 / 241 \mathrm{I}$ & $142 / 376$ & $55 \mathrm{I} / 2035$ \\
First degree-DM history (yes/no) & $209 / 2805$ & $66 / 452$ & $143 / 2443$ \\
\hline
\end{tabular}


Table 2 Risk Factors for GDM

\begin{tabular}{|l|c|c|c|c|}
\hline Factors & B & P & OR & 95\% CI \\
\hline BMI & 0.223 & 0.000 & 1.250 & $1.209-1.292$ \\
Age & 0.091 & 0.000 & 1.096 & $1.070-1.123$ \\
Height & -1.889 & $0.08 I$ & 0.151 & $0.018-1.264$ \\
GWG at 24 weeks & 0.132 & 0.000 & 1.142 & $1.108-1.176$ \\
Family history & 0.741 & 0.000 & 2.098 & $1.503-2.930$ \\
\hline
\end{tabular}

groups (28.36\% and $33.00 \%)$ was above $12 \mathrm{~kg}$ can the risk exceed the control group; therefore, $12 \mathrm{~kg}$ for GWG at 24 weeks would be the boundary for those pregnant women whose BMI was $15-21 \mathrm{~kg} / \mathrm{m}^{2}$ (Tables 3 and 4).

For pregnant women with BMI falling in the middle of $21-23 \mathrm{~kg} / \mathrm{m}^{2}, 19.16 \%$ was found to be the mean incidence rate in this group, which obviously surpasses $13.71 \%$ of the normal

Table 3 Number of GDM and Non-GDM Pregnant Women Based on BMI and Weight Gain at 24 weeks

\begin{tabular}{|c|c|c|c|c|c|c|c|c|c|c|c|}
\hline \multicolumn{2}{|c|}{ BMI $\left(\mathrm{kg} / \mathrm{m}^{2}\right)$} & \multicolumn{9}{|c|}{ GWG (kg) } & \multirow{3}{*}{$\begin{array}{l}\text { Sum } \\
58\end{array}$} \\
\hline & & \multirow{2}{*}{$\begin{array}{l}<5 \\
6\end{array}$} & \multirow{2}{*}{$\begin{array}{l}5-6 \\
7\end{array}$} & \multirow{2}{*}{$\begin{array}{l}6-7 \\
3\end{array}$} & \multirow{2}{*}{$\begin{array}{l}7-8 \\
8\end{array}$} & \multirow{2}{*}{$\begin{array}{l}8-9 \\
5\end{array}$} & \multirow{2}{*}{$\frac{9-10}{5}$} & \multirow{2}{*}{$\frac{|0-| \mid}{4}$} & \multirow{2}{*}{$\frac{11-12}{1}$} & \multirow{2}{*}{$\frac{\geq 12}{19}$} & \\
\hline $15-19$ & GDM & & & & & & & & & & \\
\hline & Non-GDM & 130 & 89 & 112 & 90 & 99 & 70 & 42 & 39 & 48 & 719 \\
\hline \multirow[t]{2}{*}{$|9-2|$} & GDM & 17 & 13 & 8 & 18 & 8 & 12 & 6 & 6 & 33 & 121 \\
\hline & Non-GDM & 147 & 105 & 107 & 128 & 123 & 89 & 60 & 50 & 67 & 876 \\
\hline \multirow[t]{2}{*}{$21-23$} & GDM & 15 & 8 & II & II & 10 & 19 & 15 & 16 & 28 & 133 \\
\hline & Non-GDM & 122 & 67 & 80 & 75 & 60 & 47 & 38 & 30 & 42 & 561 \\
\hline \multirow[t]{2}{*}{$23-25$} & GDM & 16 & 9 & 9 & 7 & 8 & 12 & 7 & 10 & 17 & 95 \\
\hline & Non-GDM & 67 & 36 & 33 & 28 & 24 & 31 & 12 & 19 & 22 & 272 \\
\hline \multirow[t]{2}{*}{$25-27$} & GDM & 9 & 2 & 7 & 8 & 5 & 2 & 5 & 0 & 10 & 48 \\
\hline & Non-GDM & 25 & II & 16 & II & 6 & 4 & 9 & 3 & 9 & 94 \\
\hline \multirow[t]{2}{*}{$\geq 27$} & GDM & 22 & 8 & 7 & 3 & 6 & 4 & 4 & 3 & 6 & 63 \\
\hline & Non-GDM & 33 & 6 & 5 & 7 & 2 & 3 & 4 & I & 3 & 64 \\
\hline
\end{tabular}

Table 4 Incidence of GDM Based on BMI and GWG at 24 weeks

\begin{tabular}{|c|c|c|c|c|c|c|}
\hline \multirow[t]{2}{*}{ GWG (kg) } & \multicolumn{6}{|l|}{ BMI $\left(\mathbf{k g} / \mathbf{m}^{2}\right)$} \\
\hline & $15-19(p=0.000)$ & $|9-2|(p=0.000)$ & $21-23(p=0.000)$ & $23-25(p=0.000)$ & $25-27(p=0.187)$ & $\geq 27(p=0.000)$ \\
\hline$<5$ & $4.41 \%$ & $10.37 \%$ & $10.95 \%$ & $19.28 \%$ & $26.47 \%$ & $40.00 \%$ \\
\hline $5-6$ & $7.29 \%$ & $11.02 \%$ & $10.67 \%$ & $20.00 \%$ & $15.38 \%$ & $57.14 \%$ \\
\hline $6-7$ & $2.61 \%$ & $6.96 \%$ & $12.09 \%$ & $21.43 \%$ & $30.43 \%$ & $58.33 \%$ \\
\hline $7-8$ & $8.16 \%$ & $12.33 \%$ & $12.79 \%$ & $20.00 \%$ & $42.11 \%$ & $30.00 \%$ \\
\hline $8-9$ & $4.81 \%$ & $6.11 \%$ & $14.29 \%$ & $25.00 \%$ & $45.45 \%$ & $75.00 \%$ \\
\hline $9-10$ & $6.67 \%$ & $11.88 \%$ & $28.79 \%$ & $27.91 \%$ & $33.33 \%$ & $57.14 \%$ \\
\hline $10-11$ & $8.70 \%$ & $9.09 \%$ & $28.30 \%$ & $36.84 \%$ & $35.71 \%$ & $50.00 \%$ \\
\hline $11-12$ & $2.50 \%$ & $10.71 \%$ & $34.78 \%$ & $34.48 \%$ & $0.00 \%$ & $75.00 \%$ \\
\hline$\geq 12$ & $28.36 \%$ & $33.00 \%$ & $40.00 \%$ & $43.59 \%$ & $52.63 \%$ & $66.67 \%$ \\
\hline Mean incidence & $7.46 \%$ & $12.14 \%$ & $19.16 \%$ & $25.89 \%$ & $33.80 \%$ & $49.61 \%$ \\
\hline
\end{tabular}


group. Still, no more than $9 \mathrm{~kg}$ of GWG at 24 weeks would be recommended as only in this condition can this group be safer than normal average incidence (Tables 3 and 4).

It is difficult to the point of impossibility for women whose BMI is above $\geq 23 \mathrm{~kg} / \mathrm{m}^{2}$ to reach the ideal level, as other groups, when the average incidence of these groups was $32.40 \%$ complicating with no junior unit was under or equal to $13.71 \%$ after being stratified twice by GWG at 24 weeks. Even so, $8 \mathrm{~kg}$ or less than $8 \mathrm{~kg}$ would be a better choice for pregnant women whose BMI was $23-25 \mathrm{~kg} / \mathrm{m}^{2}$ as risk of GDM contented with this condition was $20.00 \%$, higher than the normal one, yet reaching its lowest level of itself. However, no significant difference $(p=0.187)$ was observed for GWG at 24 weeks in BMI of $25-27 \mathrm{~kg} / \mathrm{m}^{2}$. In terms of pregnant women with BMI above $27 \mathrm{~kg} / \mathrm{m}^{2}$, we took it as no clinical significance when the number of samples was too small to be representative (Tables 3 and 4).

\section{Incidence of GDM Based on Age and Pre-BMI}

Table 5 shows that the average incidence of GDM for those whose aged under 28 years old was only $12.40 \%$ but only when pre-BMI was not more than $22 \mathrm{~kg} / \mathrm{m}^{2}$ was the incidence of each unit always lower than $13.71 \%$, so pre-BMI $\leq 22 \mathrm{~kg} / \mathrm{m}^{2}$ would be recommended for expectant mothers whose age is no more than 28 years old. Similarly, those women whose age was above 28 years old would be advised to control their BMI below $20 \mathrm{~kg} / \mathrm{m}^{2}$ while the mean incidence of GDM of this group reached $21.02 \%$.

\section{Discussion}

Well-documented risk factors for GDM include advanced maternal age, high pre-BMI, excessive weight gain during pregnancy, family history of diabetes, ethnicity, history of gestational diabetes, fertility, short stature, polycystic ovary syndrome, history of macrosomia delivery, and high systolic blood pressure. ${ }^{6,16}$ In this study, only family history of first-degree diabetes, pre-BMI, age, and weight gain before 24 weeks of pregnancy were analyzed after excluding pregnant women with other influencing factors. The present study showed that pre-BMI, first-degree family history of DM, GWG at 24 weeks, and advanced gestation age were indeed risk factors for the occurrence of GDM, among which first-degree family history of DM and gestation age are factors pregnant women cannot reverse while the other two could be intervened by improving lifestyle habits.

Obesity can lead to the accumulation of high metabolic risk factors. Obese pregnant women are prone to complications with elevated fasting plasma glucose, high glycated hemoglobin, insulin resistance, high plasma triglyceride, and hypertension during the first antenatal care. ${ }^{17}$ The number of metabolic risk factors was positively correlated with the occurrence of GDM. One mechanism is that obesity increases plasma levels of free fatty acids and introduces increasing lipid of non-fat cells. Lipid accumulation in these cells induces insulin resistance by activating protein kinase $\mathrm{C}$ and diacylglycerol pathways. ${ }^{18}$ On the other hand, insulin regulates the plasma triglyceride concentration by down-regulating microsomal triglyceride transporter (MPL) and activating lipoprotein lipase (LPL). ${ }^{19}$ On the condition of insulin resistance, if MPL cannot be inhibited or LPL cannot be promoted, hypertriglyceridemia will occur. In addition, obesity also activates the renin-angiotensin-aldosterone system, which contributes to the development of hypertension. ${ }^{20}$ Overall, obesity can cause the clustering of high-risk factors of GDM including hypertension, hypertriglyceridemia, and insulin resistance.

Table 5 Number and Incidence of GDM Based on Age and Pre-BMI

\begin{tabular}{|c|c|c|c|c|c|c|c|c|c|c|c|}
\hline \multicolumn{2}{|l|}{ Age } & \multicolumn{9}{|l|}{ BMI } & \multirow{3}{*}{$\begin{array}{l}\text { Sum } \\
182\end{array}$} \\
\hline & & \multirow{2}{*}{$\begin{array}{l}\leq 17 \\
4\end{array}$} & \multirow{2}{*}{$\frac{\mid 7-18}{7}$} & \multirow{2}{*}{$\frac{18-19}{16}$} & \multirow{2}{*}{$\begin{array}{l}19-20 \\
20\end{array}$} & \multirow{2}{*}{$\begin{array}{l}20-21 \\
20\end{array}$} & \multirow{2}{*}{$\frac{21-22}{20}$} & \multirow{2}{*}{$\begin{array}{l}22-23 \\
19\end{array}$} & \multirow{2}{*}{$\begin{array}{l}23-24 \\
19\end{array}$} & \multirow{2}{*}{$\begin{array}{l}>24 \\
57\end{array}$} & \\
\hline$\leq 28$ years old & GDM & & & & & & & & & & \\
\hline & NON-GDM & 74 & 144 & 220 & 231 & 186 & 159 & 94 & 72 & 106 & 1286 \\
\hline & Incidence $(p=0.000)$ & $5.13 \%$ & $4.64 \%$ & $6.78 \%$ & $7.97 \%$ & $9.71 \%$ & $11.17 \%$ & $16.81 \%$ & $20.88 \%$ & $34.97 \%$ & $12.40 \%$ \\
\hline \multirow[t]{3}{*}{$>28$ years old } & GDM & 3 & 8 & 20 & 36 & 45 & 50 & 54 & 37 & 93 & 346 \\
\hline & NON-GDM & 34 & 80 & 167 & 230 & 229 & 164 & 144 & 88 & 164 & 1300 \\
\hline & Incidence $(p=0.000)$ & $8.11 \%$ & $9.09 \%$ & $10.70 \%$ & $13.53 \%$ & $16.42 \%$ & $23.36 \%$ & $27.27 \%$ & $29.60 \%$ & $36.19 \%$ & $21.02 \%$ \\
\hline
\end{tabular}


First-degree diabetes is indeed a risk factor for GDM. The chance of the decedents of mothers with diabetes will be higher and it is mediated by intrauterine effect including mitochondrial genes and other gene defection, and the consequences of these congenital disadvantages will become more powerful in the modern environment of a fat-rich diet and sedentary lifestyle. ${ }^{20}$

This is the first study in China to estimate optimal GWG of 24 weeks and pre-BMI among Chinese women by weighting the occurrence of GDM. Determination of the optimal rate of gestational weight gain and pre-BMI comes from a trade-off of avoiding the incidence of GDM associated with excessive GWG at 24 weeks and those associated with inadequate gestational weight gain and higher or lower pre-BMI. Different from GWG guided by IOM, the encouraging achievements of our study presented the optimal ranges of pre-BMI and GWG at 24 weeks for expectant pregnant women and those who are already pregnant, which was based on a Chinese population and more suitable for Chinese women. Similar to the IOM, the recommendation of our research considers only one outcome: GDM, accorded with the trend of IOM only with more strict requirements and without a lower limit of the recommendation.

An ocean of studies has demonstrated that the impact of GWG rate on birth outcomes largely differs according to preBMI, ${ }^{21-23}$ which provided optimal GWG estimates utilizing the broad BMI categories of underweight $\left(<18.5 \mathrm{~kg} / \mathrm{m}^{2}\right)$, normal BMI $\left(18.5 \sim 25 \mathrm{~kg} / \mathrm{m}^{2}\right)$, overweight $\left(25 \sim 30 \mathrm{~kg} / \mathrm{m}^{2}\right)$, and obese $\left(>30 \mathrm{~kg} / \mathrm{m}^{2}\right)$. However, we choose a narrower category of BMI as more than one study shows Asians have different body composition from white women's, ${ }^{24}$ and the American Diabetes Association lowered the BMI threshold for diabetic screening among Asians from $25 \mathrm{~kg} /$ $\mathrm{m}^{2}$ to $23 \mathrm{~kg} / \mathrm{m}^{2}$ in 2014 . $^{25,26}$

Several limitations of the present study should be noticed. Firstly, our database did not include other shorttime outcomes such as LGA, small for gestational age (SGA), preterm delivery, or preeclampsia, etc., and longterm outcomes, such as childhood obesity, disordered glucose regulation in children and adolescents, cardiovascular diseases, or measurements of development of offspring, etc., so our analysis was only limited to only one of the short-term outcomes - GDM - and those outcomes should be explored. Secondly, as our study was conducted among women delivering in China only, further research to assess whether these findings are generalizable to other populations is really needed.
Thirdly, the anthropometric measurements were retrieved from antenatal clinic cards, which could potentially produce information bias and misclassification, and this study used the self-reported weight and height at first prenatal visit to calculate the pre-pregnancy BMI, which might be not reliable enough. Last but not least, the number of samples was a little small, especially as the databases were double divided although statistical significance was approved.

\section{Conclusion}

In summary, higher pre-BMI, excessive GWG before OGTT, advanced age, and family history of DM provide unique opportunities for women to develop GDM. Optimal GWG during pregnancy varies largely by pre-pregnancy BMI, and, likewise, optimal pre-BMI varies a lot by different age group. There is a need for public health awareness on the importance of having healthy pre-BMI, achieving optimal weight gain during pregnancy to avoid or reduce the incidence of GDM, especially for those with a first-degree family history of DM.

\section{Ethics Statement}

The study was approved by the ethics review board of Shanghai General Hospital and all the participants of the study gave written consent. The participants were informed about the purpose of the study, and that it was conducted in accordance with the Declaration of Helsinki. The patients were selected from those who visited antenatal clinics of Shanghai General Hospital. They belonged to ethnic groups living in rural and urban areas of Shanghai.

\section{Acknowledgments}

The authors acknowledge the help of the obstetric team in data collection for our studies.

\section{Disclosure}

The authors declare no conflicts of interest.

\section{References}

1. Metzger BE, Coustan DR, Trimble ER; HAPO Study Cooperative Research Group. Hyperglycemia and adverse pregnancy outcomes. N Engl J Med. 2008;358:1991-2002. doi:10.1056/NEJMoa0707943

2. McMahon MJ, Ananth CV, Liston RM. Gestational diabetes mellitus: risk factors, obstetric complications and infant outcomes. Reprod Med. 1998;43(4):372-378.

3. Lee AJ, Hiscock RJ, Wein P, Walker SP, Permezel M. Gestational diabetes mellitus: clinical predictors and long-term risk of developing Type 2 diabetes: a retrospective cohort study using survival analysis. Diabetes Care. 2007;30(4):878-883. doi:10.2337/dc06-1816 
4. Dabelea D, Hanson RL, Lindsay RS, et al. Intrauterine exposure to diabetes conveys risks for type- 2 diabetes and obesity: a study of discordant sibships. Diabetes. 2000;49:2208-2211. doi:10.2337/ diabetes.49.12.2208

5. Clausen TD, Mathiesen ER, Hansen T, et al. High prevalence of type- 2 diabetes and pre-diabetes in adult offspring of women with gestational diabetes mellitus or type-1 diabetes: the role of intrauterine hyperglycemia. Diabetes Care. 2008;31:340-346. doi:10.2337/ dc07-1596

6. Lee KW, Ching SM, Ramachandran V, et al. Prevalence and risk factors of gestational diabetes mellitus in Asia: a systematic review and meta-analysis. BMC Pregnancy Childbirth. 2018;18(1). doi:10. 1186/s12884-018-2131-4

7. Carpenter MW, Canick JA, Hogan JW, Shellum C, Somers M, Star JA. Amniotic fluid insulin at 14-20 weeks' gestation: association with later maternal glucose intolerance and birth macrosomia. Diabetes Care. 2001;24:1259-1263. doi:10.2337/diacare.24.7.1259

8. Chiefari E, Quaresima P, Visconti F, Mirabelli M, Brunetti A. Gestational diabetes and fetal overgrowth: time to rethink screening guidelines. Lancet Diabetes Endocrinol. 2020;8(7):561-562. doi:10. 1016/S2213-8587(20)30189-3)

9. International Weight Management in Pregnancy (i-WIP)Collaborative Group. Effect of diet and physical activity based interventions in pregnancy on gestational weight gain and pregnancy outcomes: meta-analysis of individual participant data from randomised trials. BMJ. 2017;358:j3119. doi:10.1136/bmj.j3119

10. Egan AM, Simmons D. Lessons learned from lifestyle prevention trials in gestational diabetes mellitus. Diabet Med. 2019;36:142-150. doi:10.1111/dme. 13772

11. Lean ME, Leslie WS, Barnes AC, et al. Primary care-led weight management for remission of type 2 diabetes (DiRECT): an open-label, cluster-randomised trial. Lancet. 2018;391:541-551. doi:10.1016/S0140-6736(17)33102-1

12. Sovio U, Murphy HR, Smith GC. Accelerated fetal growth prior to diagnosis of gestational diabetes mellitus: a prospective cohort study of nulliparous women. Diabetes Care. 2016;39:982-987. doi:10. 2337/dc16-0160

13. Institute of Medicine, Subcommittee on Nutritional Status During Pregnancy and Lactation. Nutrition During Pregnancy: Part I, Weight Gain: Part II, Nutrient Supplements. Washington, DC: National Academies Press; 1990.

14. Institute of Medicine \& National Research Council Committee to Reexamine IOM Pregnancy Weight Guidelines. Weight Gain During Pregnancy: Reexamining the Guidelines. Washington, DC: National Academies Press; 2009.
15. Hung TH, Hsieh TT. Pregestational body mass index, gestational weight gain, and risks for adverse pregnancy outcomes among Taiwanese women: a retrospective cohort study. Taiwan J Obstet Gynecol. 2016;55:575-581. doi:10.1016/j.tjog.2016.06.016

16. Pirjani R, Shirzad N, Qorbani M, et al. Gestational diabetes mellitus its association with obesity: a prospective cohort study. Eat Weight Disord-Stud Anorexia, Bulim Obes. 2017;22:445-450. doi:10.1007/ s40519-016-0332-2

17. Yen IW, Lee CN, Lin MW, et al. Overweight and obesity are associated with clustering of metabolic risk factors in early pregnancy and the risk of GDM. PLoS One. 2019;14(12):e0225978. doi:10.1371/ journal.pone.0225978

18. Boden G. Obesity and free fatty acids. Endocrinol Metab Clin North Am. 2008;37(3):635-646. doi:10.1016/j.ecl.2008.06.007

19. Au WS, Kung HF, Lin MC. Regulation of microsomal triglyceride transfer protein gene by insulin in HepG2 cells: roles of MAPKerk and MAPKp38. Diabetes. 2003;52(5):1073-1080. doi:10.2337/diabetes. 52.5.1073

20. Hall JE, Do Carmo JM, da Silva AA, Wang Z, Hall ME. Obesity-induced hypertension: interaction of neurohumoral and renal mechanisms. Circ Res. 2015;116:991-1006. doi:10.1161/CIRCRESAHA.116.305697

21. Li N, Liu E, Guo J, et al. Maternal pre-pregnancy body mass index and gestational weight gain on pregnancy outcomes. PLoS One. 2013;8:e82310. doi:10.1371/journal.pone.0082310

22. Choi SK, Park IY, Shin JC. The effects of pre-pregnancy body mass index and gestational weight gain on perinatal outcomes in Korean women: a retrospective cohort study. Reprod Biol Endocrinol. 2011;9:6. doi:10.1186/1477-7827-9-6

23. Ee TX, Allen JC, Malhotra R, Koh H, Ostbye T, Tan TC. Determining optimal gestational weight gain in a multiethnic Asian population. J Obstet Gynaecol Res. 2014;40:1002e1008. doi:10.1111/ jog. 12307

24. Consultation WE. Appropriate body-mass index for Asian populations and its implications for policy and intervention strategies. Lancet. 2004;363:157e163.

25. Araneta MR, Kanaya AM, Hsu WC, et al. Optimum BMI cut points to screen asian americans for type 2 diabetes. Diabetes Care. 2015;38:814e820. doi:10.2337/dc14-2071

26. Palaniappan LP, Wong EC, Shin JJ, Fortmann SP, Lauderdale DS. Asian Americans have greater prevalence of metabolic syndrome despite lower body mass index. Int $J$ Obes (Lond). 2011;35:39 3e400. doi:10.1038/ijo.2010.152

Diabetes, Metabolic Syndrome and Obesity: Targets and Therapy

Dovepress

\section{Publish your work in this journal}

Diabetes, Metabolic Syndrome and Obesity: Targets and Therapy is an international, peer-reviewed open-access journal committed to the rapid publication of the latest laboratory and clinical findings in the fields of diabetes, metabolic syndrome and obesity research. Original research, review, case reports, hypothesis formation, expert opinion and commentaries are all considered for publication. The manuscript management system is completely online and includes a very quick and fair peer-review system, which is all easy to use. Visit http://www.dovepress.com/testimonials.php to read real quotes from published authors. 